\title{
Investiagtion of Mental Health of Females with HIV-Positive Husbands Referred to Counseling and Behavioral Centers in Hamadan, Iran during 2019
}

\author{
Azar Pirdehghan', Vahideh Shakeri², Seyed Hamid Hashemi ${ }^{3}$, Saman Torkashvand ${ }^{4, *}$ \\ ${ }^{I}$ Associate Professor, Department of Community Medicine, School of Medicine, Hamadan University of Medical Sciences, \\ Hamadan, Iran \\ ${ }^{2}$ General Practitioner, Hamadan University of Medical Sciences, Hamadan, Iran \\ 3 Professor, Brucellosis Research Center, Hamadan University of Medical Sciences, Hamadan, Iran \\ ${ }^{4}$ Medical Student, Hamadan University of Medical Sciences, Hamadan, Iran \\ * Corresponding Author: Saman Torkashvand, School of Medicine, Hamadan University of Medical Sciences, Hamadan, \\ Iran.Email: samantarkashvand@gmail.com
}

\begin{tabular}{|c|c|}
\hline \multirow[b]{2}{*}{$\begin{array}{l}\text { Received: } 24.07 .2019 \\
\text { Accepted: } 17.11 .2019\end{array}$} & Abstract \\
\hline & \multirow{7}{*}{$\begin{array}{l}\text { Background and Objective: Human immunodeficiency virus (HIV) } \\
\text { infection in males not only causes physical, psychological, economic, and } \\
\text { social problems for this population, it may also affect the physical and mental } \\
\text { health of their spouses. This study aimed to compare the wives of HIV- } \\
\text { positive husbands with a control group regarding depression, anxiety, and } \\
\text { stress disorders. } \\
\text { Materials and Methods: This descriptive and cross-sectional study } \\
\text { included } 43 \text { wives of HIV-positive husbands (case group) who referred to } \\
\text { Counseling and Behavioral Centers in Hamadan and Malayer, Iran, during } \\
2019 \text { using census and convenience sampling methods. Subsequently, the } \\
\text { case group was compared with a control group (i.e., } 100 \text { wives of HIV- } \\
\text { negative husbands) in terms of depression, anxiety, and stress using } \\
\text { Depression, Anxiety, and Stress Scale- } 21 \text {. The data were analyzed in SPSS } \\
\text { software (version } 21 \text { ). A P-value less than } 0.05 \text { was considered statistically } \\
\text { significant. } \\
\text { Results: The mean values of depression, anxiety, and stress in the case and } \\
\text { control groups were } 17.44 \pm 12.32 \text { and } 5.82 \pm 7.29(\mathrm{P}<0.001), 13.20 \pm 10.42 \text { and } \\
6.56 \pm 5.75 \text { (P }<0.001 \text { ), as well as } 20.23 \pm 12.58 \text { and } 16.04 \pm 8.03 \text {, respectively } \\
\text { (P=0.049). Out of } 143 \text { females under study, } 38(26.6 \%) \text { cases were HIV- } \\
\text { positive. Moreover, the mean values of depression, anxiety, and stress in } \\
\text { HIV-positive and HIV-negative females were } 17.47 \pm 12.64 \text { and } 6.36 \pm 7.81 \\
\text { (P<0.001), } 16.82 \pm 5.88 \text { and } 13.36 \pm 10.87 \text { (P }<0.001) \text {, as well as } 20.05 \pm 12.19 \\
\text { and } 16.30 \pm 8.59 \text {, respectively (P=0.042). } \\
\text { Conclusion: The prevalence of depression, anxiety, and stress is high in } \\
\text { females with HIV-positive husbands. According to the results, there is a } \\
\text { significant relationship between depression and the level of education among } \\
\text { these women. It can be concluded that HIV-infection correlated significantly } \\
\text { with psychiatric disorders. }\end{array}$} \\
\hline \multirow{7}{*}{$\begin{array}{l}\text { How to Cite this Article: } \\
\text { Pirdehghan A, Shakeri V, } \\
\text { Hashemi SH, Torkashvand S. } \\
\text { Investiagtion of Mental Health } \\
\text { of Females with HIV-Positive } \\
\text { Husbands Referred to Counseling } \\
\text { and Behavioral Centers in } \\
\text { Hamadan, Iran during } 2019 . \\
\text { Avicenna J Clin Med. 2019; } \\
\text { 26(3): 181-187. DOI: } 10.29252 / \\
\text { ajcm.26.3.181 }\end{array}$} & \\
\hline & \\
\hline & \\
\hline & \\
\hline & \\
\hline & \\
\hline & Keywords: Anxiety, Depression, Human Immunodeficiency Virus, Stress \\
\hline
\end{tabular}




\section{بررسى وضعيت سلامت روان زنان داراى همسران HIV مثبت مراجعه كننده به مراكز بيمارىهاى رفتارى استان همدان در سال يهج |}

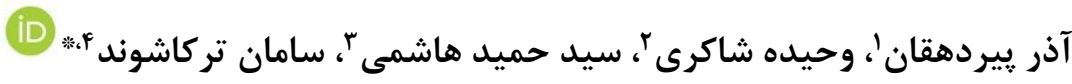

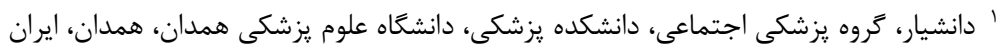

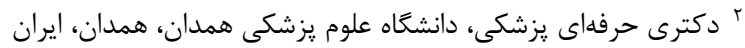

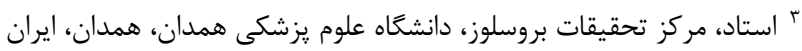

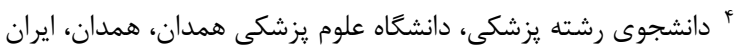

samantarkashvand@gmail.com : نويسنده مسئول: سامان تر كاشوند، دانشكده يزشكى، دانشكاه علوم يزشكى همدان، همدان، ايران. ايميل

\section{جكيده}

سابقه و هدف: ابتلا به Human Immunodeficiency Viruses) HIV) در مردان نهتنها باعث بروز

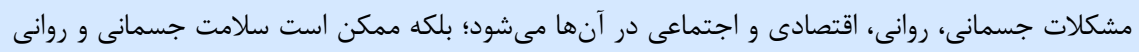

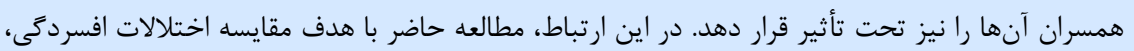

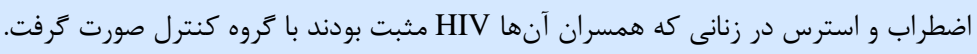

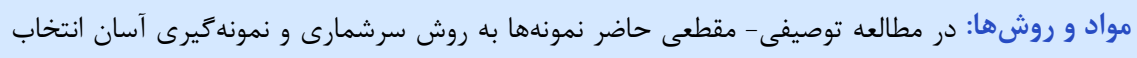

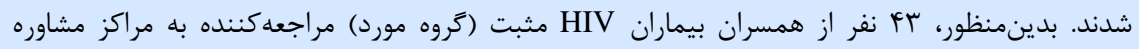

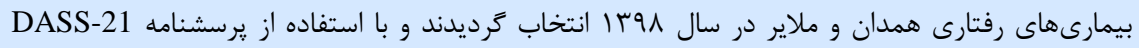
هepression, Anxiety and Stress Scales)

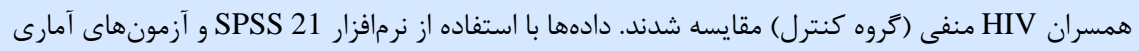

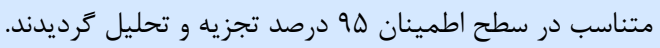

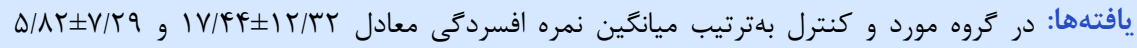

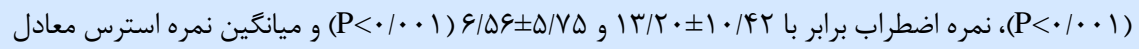
د د

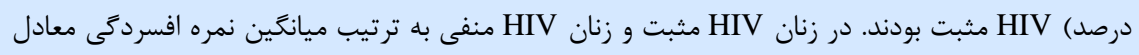

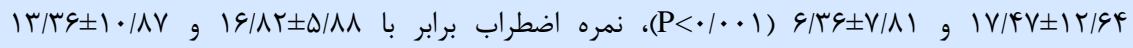

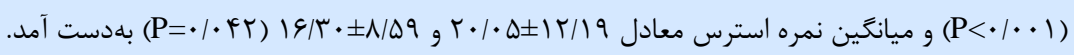

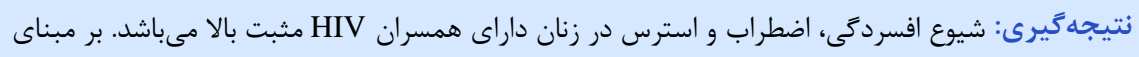

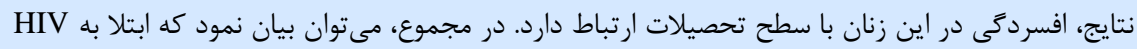
ارتباط مستقيمى با اختلالات روانى دارد.

$$
\text { واثَّان كليدى: اج آى وى، استرس، اضطراب، افسردىى }
$$

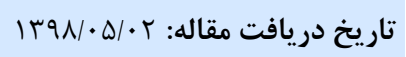

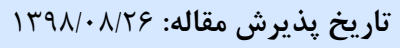
تمامى حقوق نشر براى دانشكاه علوم يزشكى همدان محفوظ است.

مقدمه

هزينهایى مراقبتى فراوان و تهديد جدى سلامت و اقتصاد جوامع

همراه مىباشد [r.r]

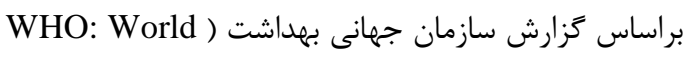
(Health Organization

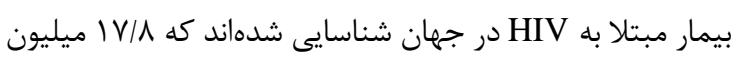

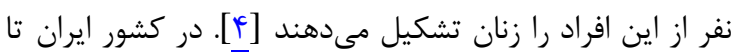

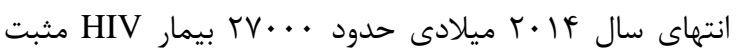

ايدز (AIDs) يكى از مخربترين معضلات جوامع كنونى

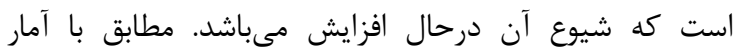

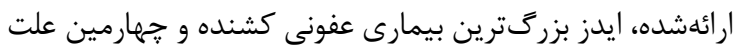

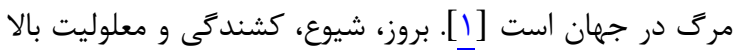

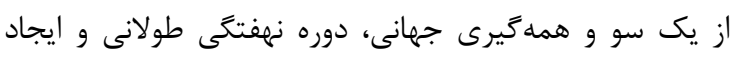

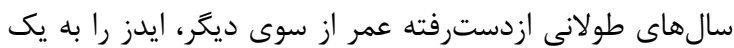

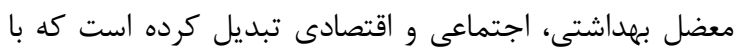


حاضر با هدف تعيين وضعيت سلامت روان زنان داراى همسران مثبت مراجعه كننده به مركز مشاوره بيمارى هاى رفاي رفتارى شهرستانهاى همدان و ملاير انجام شد.

\section{مواد و روشها}

در مطالعه توصيفى- مقطعى حاضر بَ نج نفر از زنان داراى

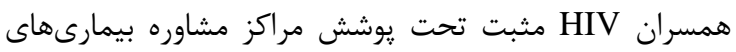

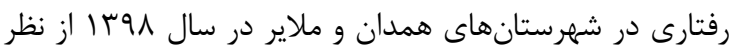

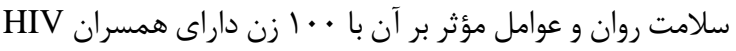
منفى بررسى ترديدند. بلمنظور سنجش اختلالات از يرسشنامه داراى سه زيرمقياس افسردگى، استرس و اضطراب مى باشد،

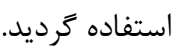

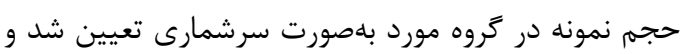

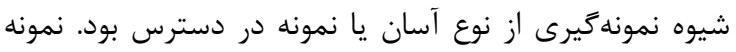

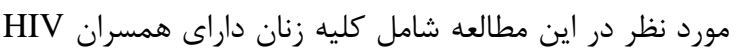
مثبتى بود كه واجد معيارهاى ورود به مطالعه بودند.

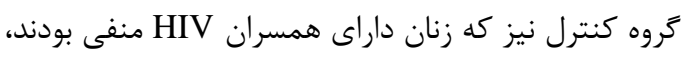

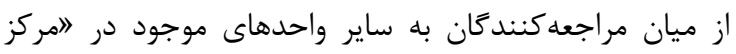

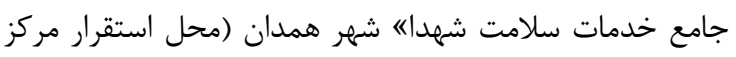

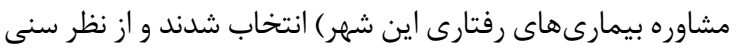

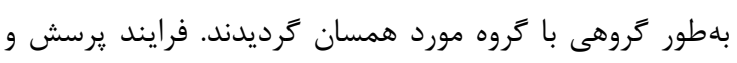

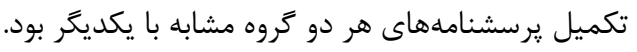

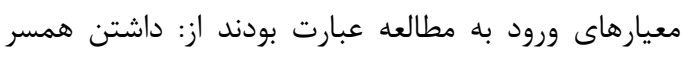

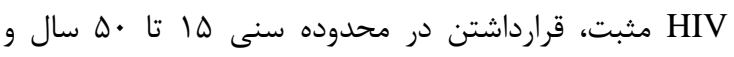

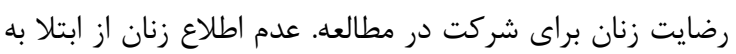

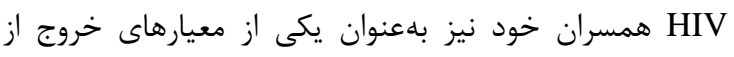
مطالعه در نظر ترفته شد. شايان ذكر است كه عدم ابتلاى خود و همسر بـ به

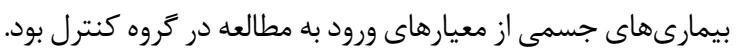

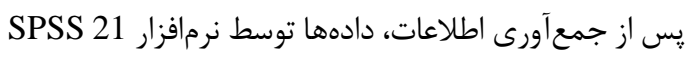

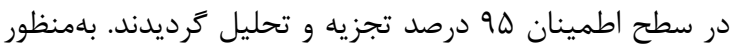

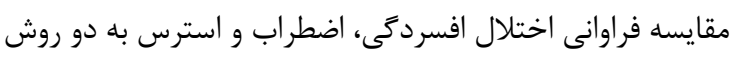

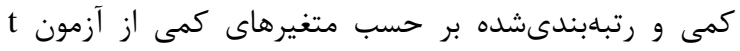

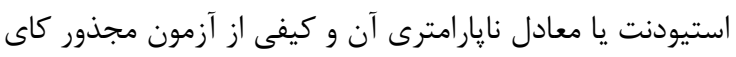

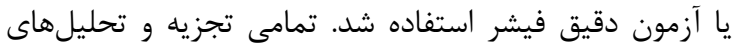

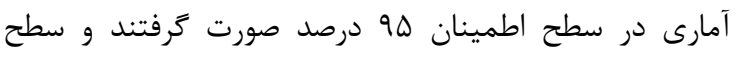
معنادارى كمتر از هـ •• در نظر كرفته شد.

\section{يافته ها}

ميانكَين سنى زنان داراى همسران HIV مثبت و كروان

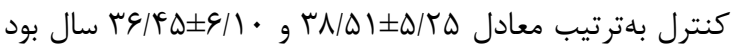

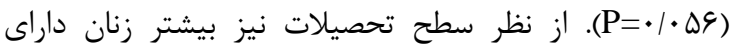

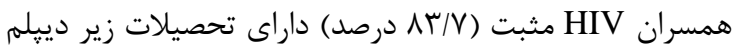

شناسايى شدند كه V/• درصد از كل موارد ثبتشده را زنان

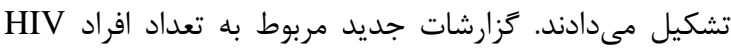

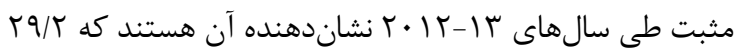

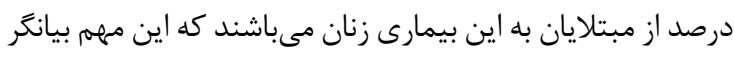

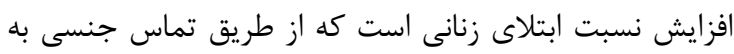
اين بيمارى آلوده شدهاند [هـان]. نتايج برخى از مطالعات حاكى از آن هستند كه بين عفونت آنان

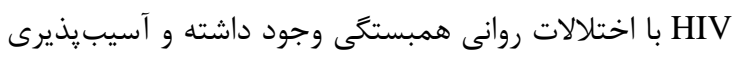

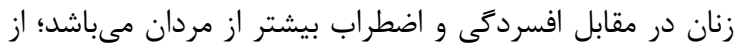

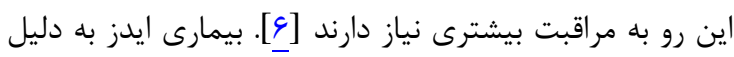

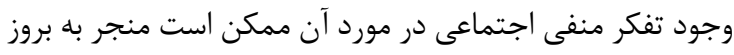

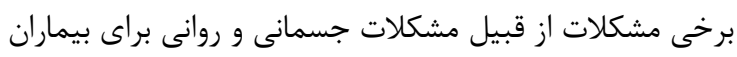

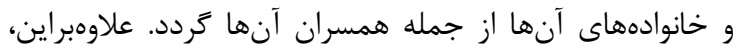

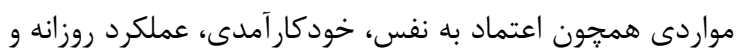
فعاليتهاى اجتماعى مبتلايان به HIV تحت تأثير ائنائ اين بيمارى

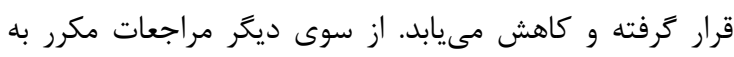

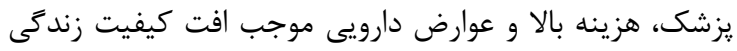

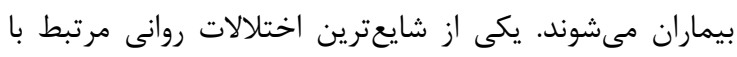

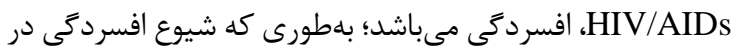

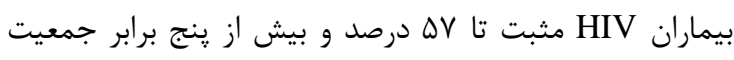

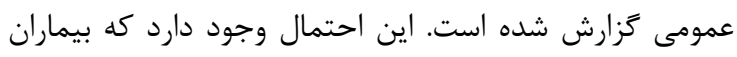

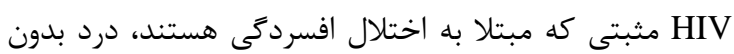

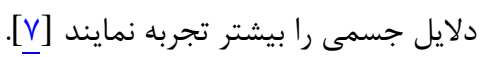

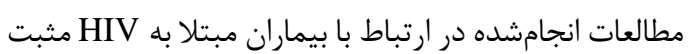

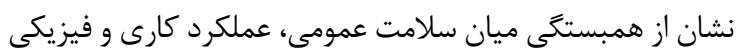

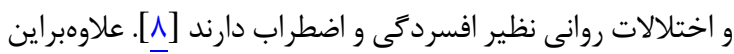

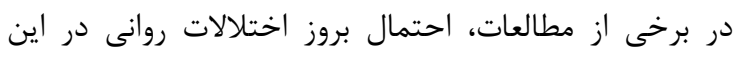

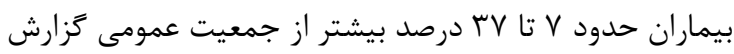

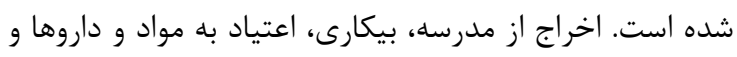

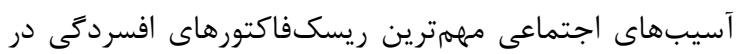

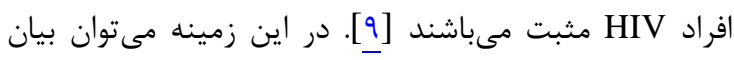

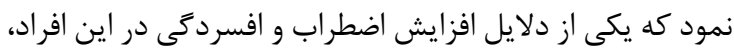

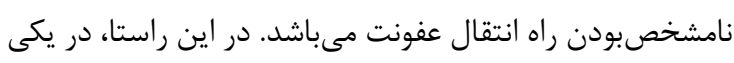

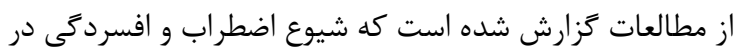

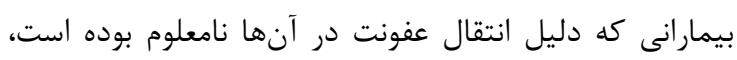

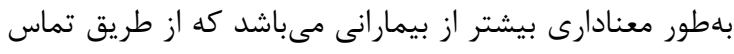

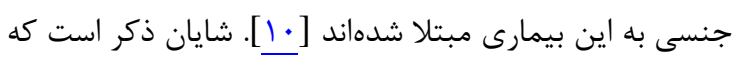

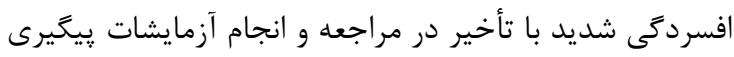

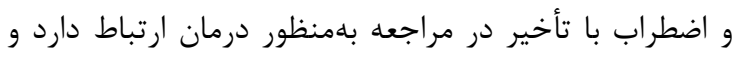

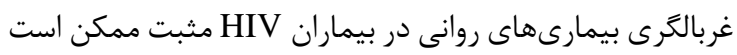

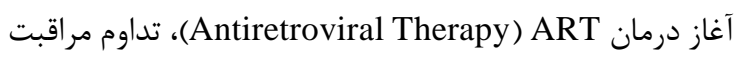
و آزمايشات يُيخيرى بيماران را بهبود بخشد [111].

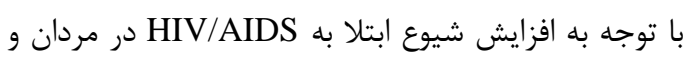
تأثير آن بر خانوادههاى آنها بهويزه همسران اين افئ افراد، مطالعه 
از زنان داراى همسران با تحصيلات دييلم و بالاتر بود

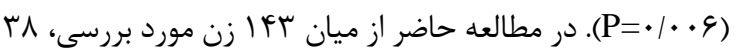

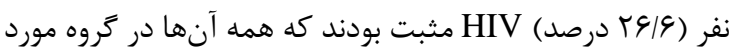
يا زنان داراى همسران HIV مثبت قرار داشتند. ميانكين نمره

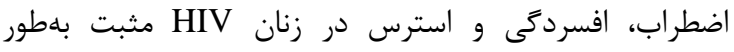

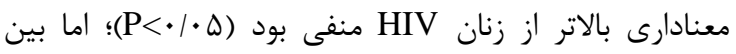
تحصيلات با اضطراب و استرس و بين سابقه اعتياد و سابقه زئه رفتارهاى يرخطر با افسردىى، استرس و اضطراب، ارتباط آمارى

$$
\text { معنادارى مشاهده نشد (جدول ؟ار). }
$$

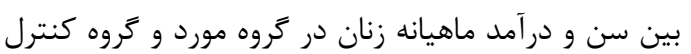

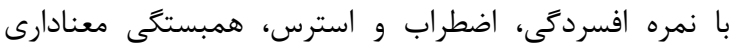

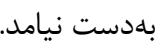

بودند و گروه كنترل (DQ درصد) تحصيلات دانشگاهى داشتند

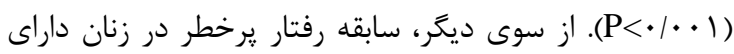

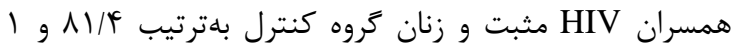

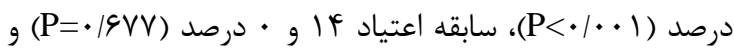

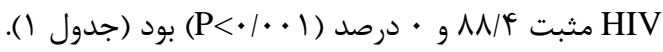

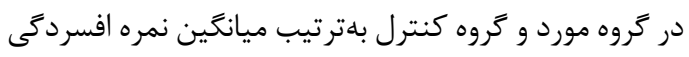
معادل

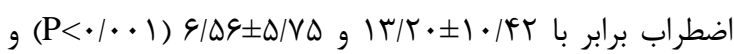

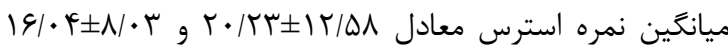

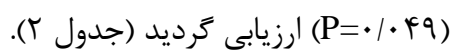

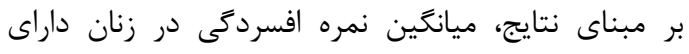

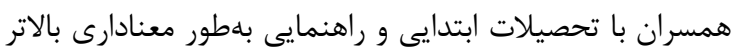

$$
\text { جدول ا: اطلاعات پايه زنان داراى همسران HIV مثبت و گروه كنترل }
$$

\begin{tabular}{|c|c|c|c|}
\hline سطح معنادارى & كنترل & مورد & \\
\hline$\cdot / \cdot \Delta \varphi^{*}$ & $(\varepsilon / / \mid \cdot) r \varepsilon / F \Delta$ & $(\Delta / T \Delta) \Gamma N / \Delta)$ & سن سانغين (انحراف معيار) \\
\hline$<\left.\cdot 1 \cdot \cdot\right|^{\text {券券 }}$ & $\begin{array}{l}(r \cdot / \cdot) T \cdot \\
(T \Delta / \cdot) T \Delta \\
(\Delta \Delta / \cdot) \Delta \Delta\end{array}$ & $\begin{array}{l}(Y \varphi / \Delta) r \cdot \\
(r V / T) \mid \varphi \\
(\mid \varepsilon / T) V\end{array}$ & تحصيلات، تعداد (درصد) \\
\hline 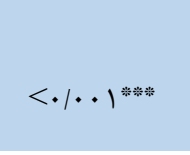 & $\begin{array}{l}(1 / \cdot)) \\
(99 / \cdot) 99\end{array}$ & $\begin{array}{l}(\Lambda \backslash / \digamma) r \Delta \\
(\mid \Lambda / \varepsilon) \wedge\end{array}$ & خله خابقه رفتار يرخطر، تعداد (درصد) \\
\hline 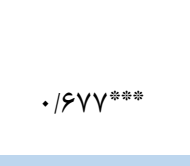 & $\begin{array}{l}(1 \cdot \cdot) \cdot \\
(\cdot) \cdot\end{array}$ & $\begin{array}{l}(\mid \uparrow / \cdot)^{q} \\
(\Lambda \varepsilon / \cdot) \mu V\end{array}$ & بله \\
\hline 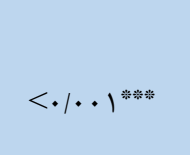 & $\begin{array}{c}(\cdot) \cdot \\
(1 \cdot \cdot) 1 \cdot \cdot\end{array}$ & $\begin{array}{l}(\Lambda \Lambda / \mathcal{F}) \Gamma \wedge \\
(1 / / q) \Delta\end{array}$ & خله \\
\hline
\end{tabular}

\begin{tabular}{|c|c|c|c|}
\hline سطح معنادارى" & كنترل & مورد - مود & \\
\hline$<\cdot / \cdot \cdot 1$ & $\Delta / \Lambda r \pm V / r q$ & $\mid V / F F \pm I T / T r$ & افسردىى \\
\hline$<\cdot / \cdot \cdot 1$ & $\varphi / \Delta \varphi \pm \Delta / v \Delta$ & $\| r / r \cdot \pm 1 \cdot / 4 r$ & اضطراب \\
\hline .1 .49 & $\mid \varepsilon / \cdot r \pm \Lambda / \cdot r$ & $r \cdot / r r \pm I r / \Delta \Lambda$ & استرس \\
\hline
\end{tabular}

جدول r: ميانگين نمره افسردگى، اضطراب و استرس در زنان كروه مورد و كنترل

مشاهده شد. بر مبناى نتايج فراوانى افسردگى، اضطراب و استرس

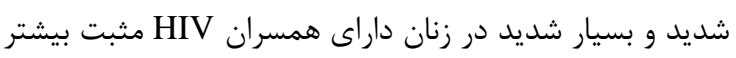

$$
\text { از خروه كنترل بود. }
$$

در اين راستا در مطالعه صورت گرفته توسط داراك و همكاران
در مطالعه حاضر ميانگين نمره افسردىى، اضطراب و استرس

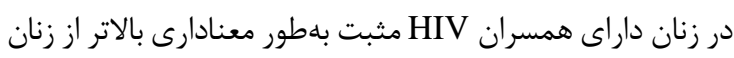

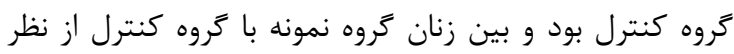

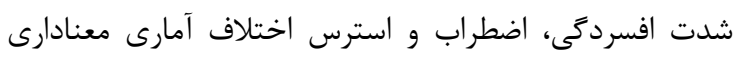


جدول س: توزيع فراوانى و ميانكين نمره افسردگى، اضطراب و استرس در زنان گروه مورد و كنترل بر حسب تحصيلات، سابقه اعتياد، رفتار يرخطر و

ابتلا به HIV

\begin{tabular}{|c|c|c|c|}
\hline ميانغين土|نحراف معيار & ميانكين+اضحراف معيار & ميانكين土|نحراف معيار & \\
\hline $\begin{array}{c}1 \Delta / 9 \Delta \pm 9 / \Delta V \\
|\wedge / \wedge \Lambda \pm| \cdot / \cdot r \\
|V /| r \pm q / V F \\
\cdot / \Delta \Delta \Delta\end{array}$ & $\begin{array}{c}\Lambda / V \cdot \pm V / \Lambda F \\
q / r V \pm q / V T \\
V / q r \pm V / F \\
\cdot / \Lambda \cdot \varphi\end{array}$ & $\begin{array}{c}1 \cdot 19 \Delta \pm 9 / \Lambda F \\
1 \cdot 10 \Lambda \pm 1 Y / 9 r \\
V / F T \pm 9 / 19 \\
\cdot / \cdot 1 F\end{array}$ & 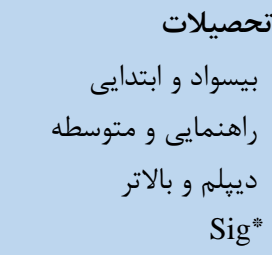 \\
\hline $\begin{array}{c}r r / \cdot \cdot \pm I r / \wedge \Delta \\
\mid V / \cdot q \pm q / V q \\
\cdot / r r .\end{array}$ & $\begin{array}{c}|\varepsilon / 4 \cdot \pm| \psi / \mid \varepsilon \\
\Lambda / Y \mid \pm N / \cdot V \\
\cdot / \cdot \Lambda \Delta\end{array}$ & $\begin{array}{c}|\Delta / r r \pm| r / q \uparrow \\
q / \cdot r \pm 1 \cdot / \Delta \Delta \\
\cdot / 1 \Delta r\end{array}$ & 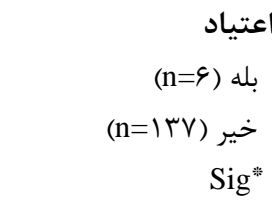 \\
\hline $\begin{array}{c}r \cdot / \cdot \Delta \pm 1 r / 19 \\
19 / T \cdot \pm N / \Delta 9 \\
\cdot / \cdot r r\end{array}$ & $\begin{array}{c}\mid \varepsilon / \Lambda Y \pm \Delta / \Lambda \Lambda \\
|r / \mu \varepsilon \pm| \cdot \mid \Lambda V \\
<\cdot / \cdot \mid\end{array}$ & 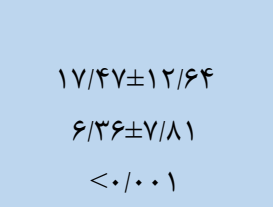 & 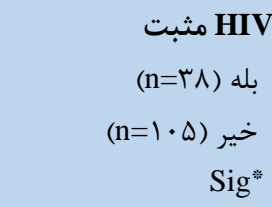 \\
\hline $\begin{array}{c}\mid V / \Delta \& \pm 9 / 9 q \\
\mid V / r \wedge \pm q / 99 \\
. / 99 Y\end{array}$ & $\begin{array}{c}\mid r / F \Delta \pm q / q q \\
\Lambda / T \cdot \pm V / V \Lambda \\
\cdot / r \& q\end{array}$ & $\begin{array}{c}|r / \cdots \pm| r / A r \\
q / \cdot \pm \mid \cdot / r r \\
\cdot / r T g\end{array}$ & 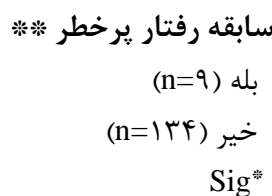 \\
\hline
\end{tabular}

** آزمون من-ويتنى؛ **** اعتياد تزريقى، رفتار جنسى يرخطر و سابقه زندان

سعادت و همكاران نيز در مطالعهاى در زمينه مقايسه

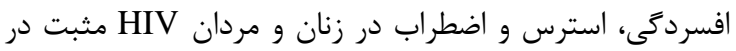

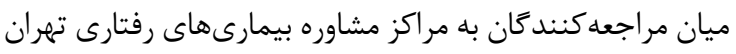

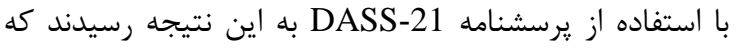

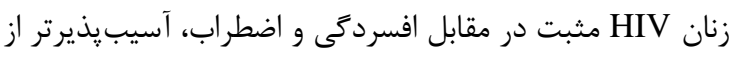

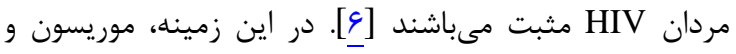

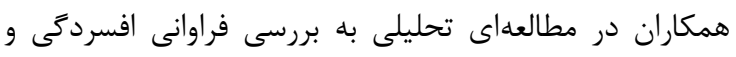

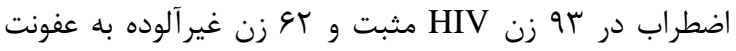

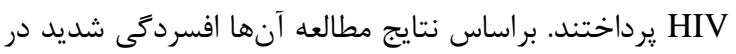

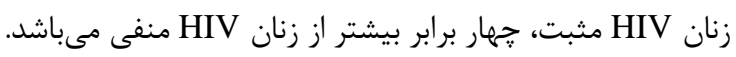

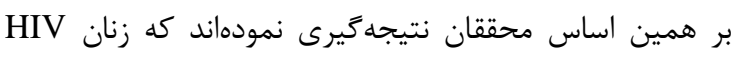

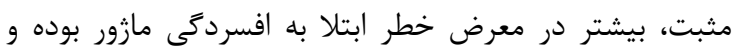

نشانهاى بيشترى از افسردىى و اضطراب را دارند [I If].

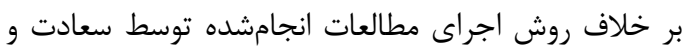
همكاران و موريسون و همكاران، در مطالعه حاضر بهجان مقاى مقايسه

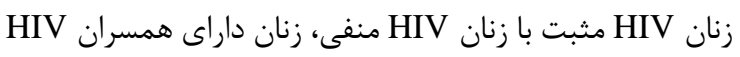

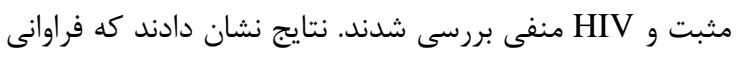

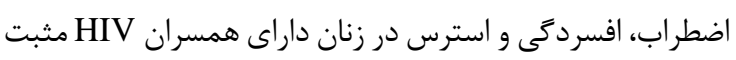
بلهطور معنادارى بالاتر از زنان داراى همسران مىباشد.

بيماران HIV مثبت در هر مرحله از بيمارى در معرض خطر

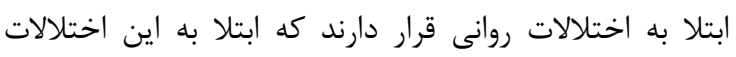

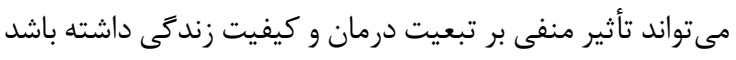

در كشور هند در سال 9 ـ • د در مورد اختلالات روانى شايع در

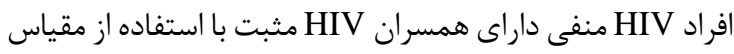
،International Classification of Diseases) ICD-10 شيوع حداقل يكى از اختلالات روانى در زنان داراى همسران مIV داراى همسران HIV مثبت مورد بررسى قرار كرفتند؛ با اين

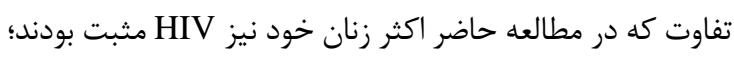

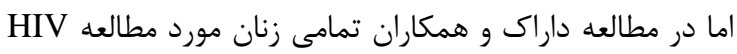

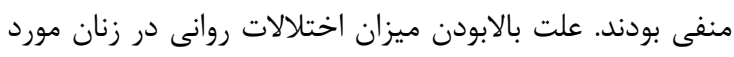

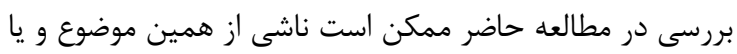
متفاوتبودن ابزارهاى سنجش اختلال روان باشد.

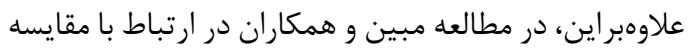

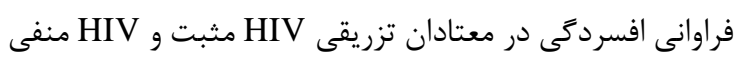

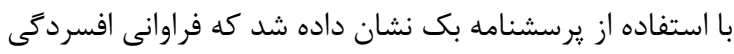

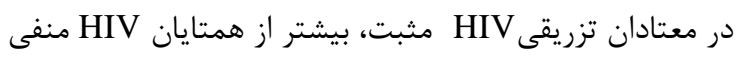

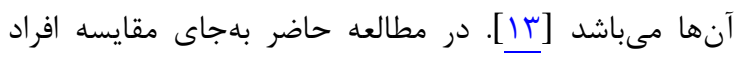

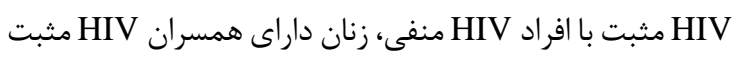

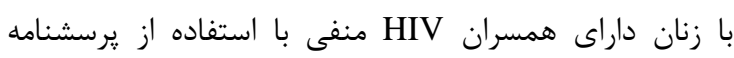

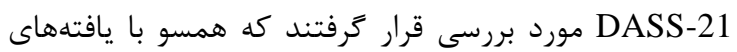
آنها فراوانى افسردگى، اضطراب و استرس شديد و بسيار شديد

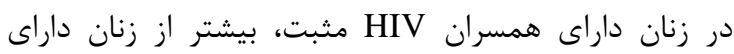

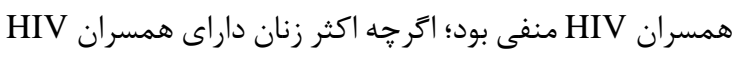
مثبت، خود نيز HIV مثبت بودند. 
همجنين توصيه مى گردد كه بهمنظور شناخت دقيقتر نقش ابتلا

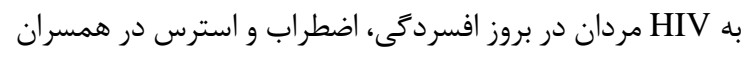
آنها، انجام مطالعات كوهورت با حجم نمونه بيشتر صورت كيرد.

\section{نتيجه كيرى}

خطر ابتلا به افسردگى، اضطراب و استرس در زنانى كه

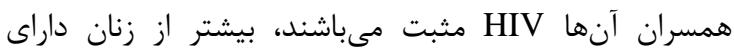
همسران HIV منفى است. همجنين اعتياد همسر و تحصيلات

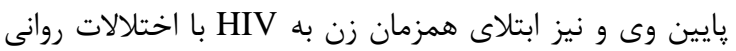

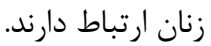

\section{تشكر و قلدر داذى}

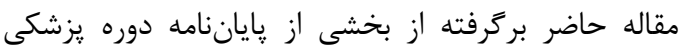

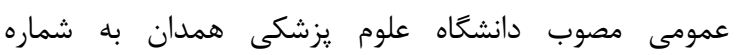

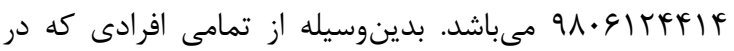
اجراى طرح و تردآورى دادهها مشاركت داشته و با محققان بدان همكارى نمودند، تقدير و تشكر مى كرد ودرد.

تضاد منافع هيج گونه تعارض منافعى بين نويسندًان و نتايج مطالعه

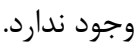

\section{ملاحظات اخلاقى}

مطالعه حاضر مورد تأييد كميته اخلاق در يزوهش دانشخاه

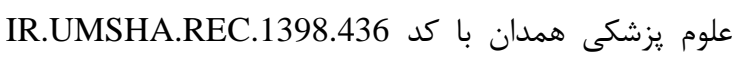

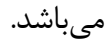

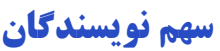

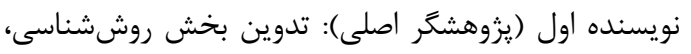

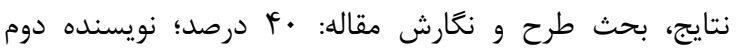

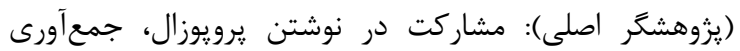

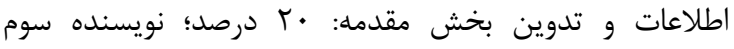

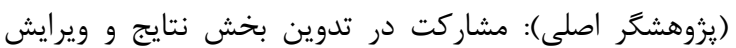

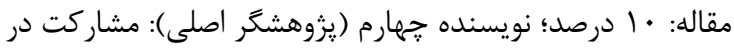

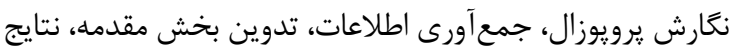

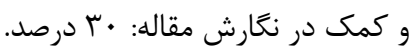

\section{حمادت مالذي}

مطالعه حاضر از سوى معاونت تحقيقات و فناورى دانشگاه علوم يزشكى همدان يشتيبانى مالى شده است.

\section{REFERENCES}

1. Zareban I, Heydarnia AR, Rakhshani F, Jabari H. Efficacy of AIDS prevention training program on knowledge, attitude and practice of Chabahar sailors, Iran. Zahedan J Res Med Sci. 2006;8(9):29-36. [Persian]

2. Tayeri K, Kasaeian N, Ataei B. The prevalence of hepatitis
و موجب افزايش رفتارهاى يرخطر در اين افراد شود [ها]]. در

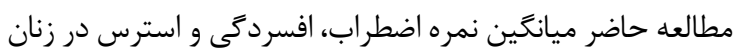
مثبت بهطور معنادارى بالاتر از زنان غيرمبتلا بهدست آمدره

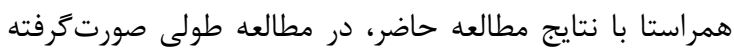

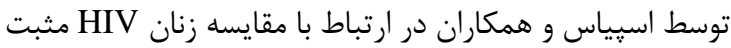

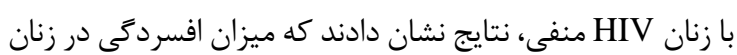

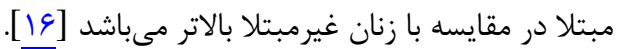

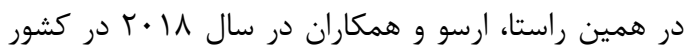
رومانى، طى مطالعهاى ارتباط بين شدت بالينى

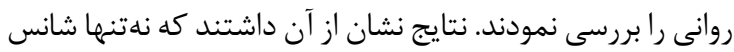

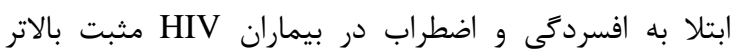

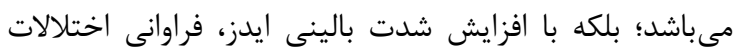

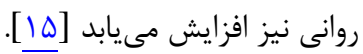
از سوى ديخر، از نظر ساير متغيرهاى مؤثر بر سلامت روابد روان بايد كفت كه در مطالعه حاضر ارتباط آمارى معنادارى ميان

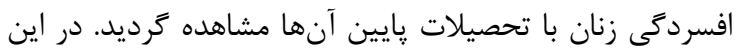

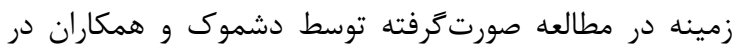

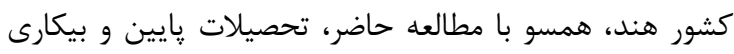

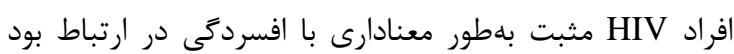

علاوهبراين، در مطالعه حاضر بين اعتياد و رفتارهاى يرخطر

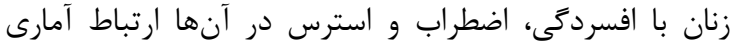

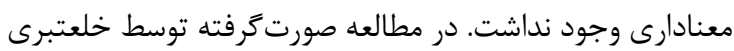

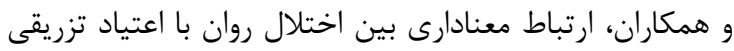

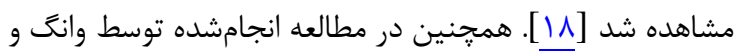

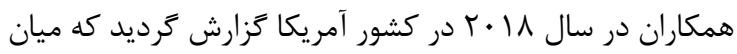
ابتلا به افسردگى و سوءمصرف مواد، همبستخى مثبتى وجود دار دارد

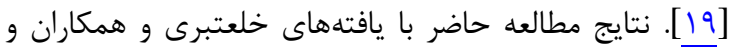

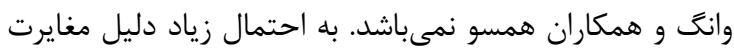

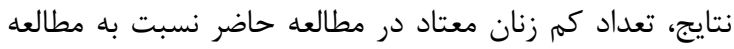

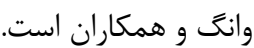
در انتها، در ارتباط با محدوديتهاي ايت اين مطالعه مىتوان به

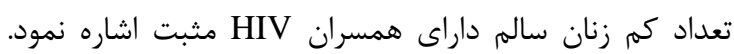
علاوهبراين، بيش از • ^ درصد از جمعيت هدف در دران مطالعه حاضر

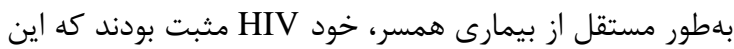

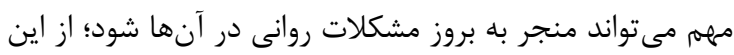

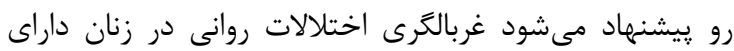

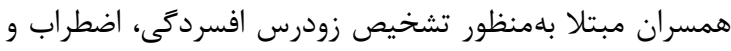

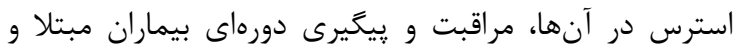

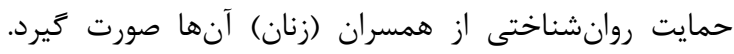

$\mathrm{B}$, hepatitis $\mathrm{C}$ and associated risk factors in intravenous drug addicts (IVDA) with HIV in Isfahan. J Isfahan Med School. 2008;26(90):273-8. [Persian]

3. Rahmati NK, Niknami S, Ahmadi F, Jafari M, Rahnama P. The implication of health belief model in planning 
educational programms for preventing HIV/AIDS among university students. Payesh. 2009;8(4):10. [Persian]

4. Who U, Unicef. Global report: UNAIDS report on the global AIDS epidemic 2016. Geneva: UNAIDS; 2016.

5. National AIDS Committee Secretariat. Islamic Republic of Iran AIDS progress Rreport. Tehran: National AIDS Committee Secretariat; 2015. [Persian]

6. Saadat M, Behboodi ZM, Saadat E. Comparison of depression, anxiety, stress, and related factors among women and men with human immunodeficiency virus infection. $J$ Hum Reprod Sci. 2015;8(1):48-51. PMID: 25838749 DOI: 10.4103/0974-1208.153128

7. Valente SM. Depression and HIV disease. $J$ Assoc Nurses AIDS Care. 2003;14(2):41-51. PMID: 12698765 DOI: $10.1177 / 1055329002250993$

8. Orlando M, Tucker JS, Sherbourne CD, Burnam MA. A cross-lagged model of psychiatric problems and healthrelated quality of life among a national sample of HIV-positive adults. Med Care. 2005;43(1):21-7. PMID: 15626930

9. Stall R, Mills TC, Williamson J, Hart T, Greenwood G, Paul $\mathrm{J}$, et al. Association of co-occurring psychosocial health problems and increased vulnerability to HIV/AIDS among urban men who have sex with men. Am J Public Health. 2003;93(6):939-42. PMID: 12773359 DOI: $10.2105 /$ ajph.93.6.939

10. Demirel O, Mayda P, Yıldız N, Sağlam H, Koçak BT, Habip $\mathrm{Z}$, et al. Self-stigma, depression, and anxiety levels of people living with HIV in Turkey. Eur J Psychiatry. 2018;32(4):1826. DOI: 10.1016/i.ejpsy.2018.03.002

11. Rane MS, Hong T, Govere S, Thulare H, Moosa MY, Celum $\mathrm{C}$, et al. Depression and anxiety as risk factors for delayed care-seeking behavior in HIV positive individuals in South Africa. Clin Infect Dis. 2018;67(9):1411-8. PMID: 29659757 DOI: $10.1093 /$ cid/ciy309

12. Darak SS, Pawar SR, Phadke SS, Kulkarni VV. Common mental disorders among HIV-uninfected women living in HIV serodiscordant setting: A clinic-based study in Pune, Maharashtra, India. Indian J Public Health. 2019;63(1):4450. PMID: 30880737 DOI: $10.4103 /$ ijph.IJPH 11218

13. Mobaein AR, Farhadi nasab A. Compression of depression frequency in hiv positive and HIV negative among IV drug abusers. J Guilan Univ Med Sci. 2011;19(76):71-6. [Persian]

14. Morrison MF, Petitto JM, Ten Have T, Gettes DR, Chiappini MS, Weber AL, et al. Depressive and anxiety disorders in women with HIV infection. Am J Psychiatry, 2002; 159(5):789-96. PMID: 11986133 DOI: 10.1176/appi. ajp.159.5.789

15. Ursoiu F, Moleriu L, Lungeanu D, Puschită M. The association between hiv clinical disease severity and psychiatric disorders as seen in western romania. AIDS Care. 2018;30(11):1368-71. PMID: 29592527 DOI: 10.1080/ 09540121.2018.1455959

16. Spies G, Konkiewitz EC, Seedat S. Incidence and persistence of depression among women living with and without HIV in South Africa: a longitudinal study. AIDS Behav. 2018; 22(10):3155-65. PMID: 29476437 DOI: 10.1007/s10461018-2072-y

17. Deshmukh NN, Borkar AM, Deshmukh JS. Depression and its associated factors among people living with HIV/AIDS: can it affect their quality of life? J Family Med Prim Care. 2017;6(3):549-53. PMID: 29417006 DOI: $10.4103 / 2249-$ 4863.222016

18. Khalatbari J, Bazarganiyan N. Comparison the depression, anxiety and stress in intravenous drug abusers, with and without HIV/ AIDS. J Guilan Univ Med Sci. 2011;20(78):7683. [Persian]

19. Wang K, Burton CL, Pachankis JE. Depression and substance use: towards the development of an emotion regulation model of stigma coping. Subst Use Misuse. 2018;53(5):859-66. PMID: 29125383 DOI: 10.1080/10826084.2017.1391011 